\title{
Over-expression of MEOX2 promotes apoptosis through inhibiting the PI3K/Akt pathway in laryngeal cancer cells
}

\author{
L. TIAN ${ }^{1}$, Z. Z. TAO ${ }^{1, *}$, H. P. YE², G. Y. $\mathrm{LI}^{3}$, Z. F. ZHAN ${ }^{3}$, H. W. TUO \\ ${ }^{1}$ Department of Otolaryngology, Head and Neck Surgery, Renmin Hospital of Wuhan University, Wuhan, Heibei Province, China; ${ }^{2}$ Department \\ of Otolaryngology, Head and Neck Surgery, Affiliated Hospital of Guizhou Medical University, Wuhan, China; ${ }^{3}$ Department of Otolaryngology, \\ Head and Neck Surgery, Taihe Hospital, Shiyan, China
}

${ }^{*}$ Correspondence: zezhangtao88zzt@163.com

Received December 18, 2017 / Accepted March 9, 2018

\begin{abstract}
Early-stage diagnosis and treatment for the recurrence of carcinoma of the larynx requires further investigation. Mesenchyme homeobox 2 (MEOX2) was speculated as a novel suppressor gene in laryngeal carcinoma and the molecular mechanism was studied. Real-time quantitative PCR (RT-qPCR) and Western blot detected MEOX2 mRNA and protein levels in laryngeal cancer tissues and cells (Hep-2, TU212, AMC-NH-8 and TU686 cells), and also apoptosis and phosphoinositide 3-kinase (PI3K)/protein kinase (Akt) related factors in TU212 cells transfected with MEOX2. Cell counting kit-8 (CCK8) assay and Annexin-V/PI staining assay respectively determined the cell viability and apoptosis rates in the 46 laryngeal carcinoma patients in this study. The expression of MEOX2 was lower in larynx carcinoma tissues than normal tissues, and it correlated with the clinical stage, differentiated degree and survival time. The expression of MEOX2 was the lowest in those laryngeal cancer cells, so it was chosen for transfection in the following study. Over-expression of MEOX2 inhibited cell viability and promoted apoptosis of TU212 cells by increasing the expression levels of Caspase-3, and decreasing the levels of C-Myc, XIAP, PI3K p110a, PI3K p110ß, PI3K class III and p-Akt. In summary, the expression levels of MEOX2 were inhibited in laryngeal carcinoma compared to normal laryngeal tissue and it correlated with cancer progression. Over-expression of MEOX2 in laryngeal cancer cells inhibited cell viability and promoted apoptosis by regulating apoptosis and PI3K/Akt pathway-related factors. This provides excellent evidence for MEOX2 use as a therapeutic gene in laryngeal carcinoma.
\end{abstract}

Key words: MEOX2, cell apoptosis, laryngeal cancer, PI3K/Akt pathway

Carcinoma of the larynx is one of the most common malignant tumors in otolaryngology; accounting for $8.4 \%$ of all malignant tumors (Statistics of China Medical University in 1983), and it ranks second in the head and neck epithelium-deprived primary malignant tumors, $90 \%$ of which were squamous cell carcinoma [1]. The incidence of laryngeal cancer is increasing because of increased exposure to a carcinogenic environment and the impact of different carcinogenic factors, [2]. Laryngeal cancer has significant gender differences; the incidence in men is approximately 10 times that of women [3]. Complicated treatment of surgical treatment and radiation therapy are used for patients with laryngeal cancer. While these can improve the annual survival rate, some patients died from tumor recurrence or distant metastasis [4]. Due to the lack of diagnostic techniques in the earlystages, many patients with laryngeal cancer are diagnosed in the late stages, thus missing the optimal treatment time [5]. The exact cause, pathogenesis and carcinogenesis of laryngeal cancer are not very clear, and therefore the early diagnosis and treatment of its recurrence is unresolved. However some clinical data and basic experimental results have shown that smoking, drinking alcohol and human papilloma virus infection are the leading risk factors for laryngeal cancer incidence [6]. In addition, the role of genetic factors in the pathogenesis of laryngeal cancer is also gradually recognized. While the proto-oncogene may be related to the carcinogenesis, the mutation and inactivation of tumor suppressor genes could also be prime laryngeal cancer mechanisms [7-9].

The mesenchyme homeobox (MEOX) family has two homeodomain proteins, MEOX1 and MEOX2, with 95\% sequence identity in the homeodomain region [10]. Both are needed for proper bone and muscle development in mouse embryos [11]. MEOX2 is also known as a specific growth arrest homeobox protein (Gax) and it is stimulisensitive and can be inhibited by stimuli [12]. MEOX2 can also inhibit cell proliferation and epithelial-to-mesen- 
chymal transition (EMT) in vascular smooth muscle and endothelial cells $[13,14]$, and it is associated with drug resistance and therapy prognosis in lung cancer [15]. Whether MEOX2 is associated with larynx carcinoma has not been fully investigated.

Organisms conduct development, differentiation, metabolism and other normal physiological activities through accurate multi-level internal regulation mechanisms. Hence, cells lose correct temporal regulation of cell differentiation, proliferation, apoptosis and other processes when regulatory system disorders occur, and normal tissue morphology can then undergo malignant transformation to tumors. Phosphoinositide 3-kinase (PI3K)/protein kinase (Akt) signaling is an important pathway involved in the activation of anti-apoptotic mechanisms, glucose metabolism and protein synthesis which all promote normal organism cell growth and proliferation [16]. Abnormal activation of PI3K/ Akt signaling is therefore closely associated with the progression of most cancers [17-19]. PI3K/Akt is also reported to participate in the progression of head and neck squamous cell carcinomas [20-22], and if $\mathrm{MEXO} 2$ has an inhibitory function in laryngeal cancer it may act through the PI3K/ Akt pathway.

Therefore, we aimed to identify MEOX2 function in carcinoma of the larynx and to study molecular mechanisms in laryngeal cancer cells, especially in relation to the PI3K/ Akt signaling pathway. Our results are expected to provide possible novel treatment of laryngeal carcinoma.

\section{Patients and methods}

Patients and tissues. Human laryngeal carcinoma tissue and normal tissue $2 \mathrm{~cm}$ distant was collected from 46 male patients aged 50 to 70 years old in the Renmin Hospital of Wuhan University between May 2016 and May 2017. The patient history and pathological diagnoses accompanied the samples. All were diagnosed with squamous cell carcinomas; with 15 patients in the I/II stages and 31 in III/IV stages, and none had received radiotherapy or chemotherapy before total laryngectomy. The study was approved by the institu-

Table 1. The primer sequences applied in this study.

\begin{tabular}{lll}
\hline Name & Type & Sequence \\
\hline \multirow{2}{*}{ MEOX2 } & Forward & CCAACGAAGAGGGCATGTTT \\
& Reverse & GGAAGAGTTGGAGCACAGGA \\
C-Myc & Forward & ATTCTCTGCTCTCCTCGACG \\
& Reverse & CTGTGAGGAGGTTTGCTGTG \\
Caspase-3 & Forward & TGAGCCATGGTGAAGAAGGA \\
& Reverse & TCGGCCTCCACTGGTATTTT \\
XIAP & Forward & AGCAGTTGGAAGACACAGGA \\
& Reverse & GCAGGGTTCCTCGGGTATAT \\
GAPDH & Forward & CCATCTTCCAGGAGCGAGAT \\
& Reverse & TGCTGATGATCTTGAGGCTG \\
\hline
\end{tabular}

tional review board of the independent ethics committee, with informed consent from patients. RT-qPCR and Western blot analyses then compared MEOX2 expression levels in the cancerous and normal tissues.

Cell culture. Human laryngeal cancer cells, including Hep-2, TU212, AMC-NH-8 and TU686 cells were purchased from Shanghai Institute Chinese Academy of Sciences (Shanghai, China). Roswell Park Memorial Institute 1640 (RPMI 1640; Gibco, USA); then 10\% fetal bovine serum (FBS; Gibco, USA) and 1\% penicillin and streptomycin (Invitrogen, USA) were used to culture the cells in $5 \% \mathrm{CO}_{2}$ and $50 \%$ humidity $(37 \mathrm{C}$ ). Cells of logarithmic phase were applied in following studies, and RT-qPCR and Western blot detected and compared MEOX2 expression in the different cell lines.

Cell transfection. TU212 cells were plated in 12-well plates at $6 \times 10^{4}$ cells/well concentration and transfected with MEOX2 over-expressed recombinant plasmid (pcDNA3.1MEOX2) or empty plasmid vector, using lipofectamine 2000 transfection reagent (Invitrogen, USA). The transfected cells are referred to as MEOX2 and $\mathrm{NC}$ groups respectively, and cells without treatment formed the Control group. The cell transfection efficiency on MEOX2 expression levels was then detected by RT-qPCR and Western blot assays.

Cell viability assay. Cell viability after transfection was determined by cell counting kit-8 (CCK8; Beyotime, Nantong, China) at determined times. Cells were cultured in 96-well plates at $5 \times 10^{3}$ cells/well density for 12,24 and 48 hours. CCK- 8 reagent $(20 \mu \mathrm{l})$ was then added and cells were cultured for a further hour. The production of soluble formazan was detected, and optical density (OD) values were measured at $450 \mathrm{~nm}$ by microplate reader (Biotek, USA).

Cell apoptosis assay. The cell apoptosis rates after 48 hours transfection were determined by Annexin-V/PI double staining assay. Cells $\left(1 \times 10^{6}\right.$ cells/well $)$ were cultured in 6-well plates for 24 hours, harvested and stained with $5 \mu$ Annexin $\mathrm{V}$-allophycocyanin for 30 minutes at $4{ }^{\circ} \mathrm{C}$ in the dark. This was followed by staining with $10 \mu \mathrm{l}$ propidium iodide (PI) (BD, USA). Apoptotic rates were analyzed by BD C6 flow cytometer (Beckton Dikinson, USA) and the early and late apoptotic cells were included in the quantification. Representative data of three independent assays are presented.

Realtime quantitative polymerase chain reaction (RT-qPCR). RT-qPCR detected mRNA expression levels in the tissues and cells. Total RNA extracted by Trizol reagent (Invitrogen, USA) was reversely transcribed to cDNA using PrimeScript RT Master Mix (Takara, Japan). The primers of MEOX2, C-Myc, Caspase-3, XIAP and GAPDH were synthesized by Invitrogen Company, and the sequences are displayed in Table 1. GAPDH was used as internal control. The program of PCR amplification included pre-denaturation at $95^{\circ} \mathrm{C}$ for 15 seconds, 40 cycles of denaturation $\left(95^{\circ} \mathrm{C}\right.$, 5 seconds) and annealing/extension $\left(60^{\circ} \mathrm{C}\right.$ for 35 seconds), using SYBR Premix Ex Taq (Takara, Japan) in ABI 7300 Thermocycler (Applied Biosystems, USA). The $2^{-\Delta \Delta \mathrm{Cq}}$ method 
was applied for quantification and the relative expression was normalized to GAPDH. All experiments were performed in triplicate.

Western blot. The expression levels of proteins (MEOX2, C-Myc, Cleaved-caspase-3, XIAP, PI3K p110a, PI3K p110ß, PI3K class III, p-Akt, Akt and GAPDH) were measured by Western blot. Extracted proteins were quantified by bicinchoninic acid assay (BCA) assay (Beyotime, Nantong, China), according to the factory's instructions. Total proteins were then separated by $10 \%$ sodium dodecyl sulfate-polyacrylamide gel electrophoresis (SDS-PAGE) with $20 \mu \mathrm{g}$ protein in every lane and then transferred to polyvinylidene fluoride (PVDF) membranes (ThermoFisher, USA). The membranes were blocked with $5 \%$ non-fat dried skimmed milk for 1 hour and incubated with specific primary antibodies at $4{ }^{\circ} \mathrm{C}$ overnight. The antibodies were purchased from Abcam (USA) and CST (USA) companies and GAPDH was used as loading control. Subsequently, the membranes were incubated with appropriate horseradish peroxidase (HRP) -conjugated secondary antibodies (Abcam, USA) at $37^{\circ} \mathrm{C}$ for 1 hour. Immunoreactive bands were then exposed to X-ray film and detected by enhanced chemiluminescense (ECL) reagents (ThermoFisher, USA). Finally, protein quantities were calculated using Quantity One software 3.0 (Bio-Rad, USA). All experiments were repeated three times. The antibodies used in the study were present as follows: rabbit anti-MEOX2 (Abcam, ab174116, 1:500), C-Myc (Abcam, ab39688, 1:1000), Cleaved-caspase-3 (Abcam, ab2302, 1:200), XIAP (Abcam, ab21278, 1:1000), PI3K p110a (CST, 4249, 1:1000), PI3K p110ß (CST, 3011, 1:1000), PI3K class III (CST, 4263, 1:1000), p-Akt (CST, 4058, 1:1000), Akt (CST, 4685, 1:1000) and GAPDH (Abcam, ab9485, 1:2000).

Statistical analysis. Statistical analyses used SPSS 22.0 (SPSS, USA). The data from each triplicate assay is presented as mean \pm standard deviation. Equivalence statistical significance was determined by Student t-test and one-way analysis of variance (ANOVA). The categorical variable was determined by Chi-square test and survival analysis was analyzed by Kaplan-Meier assay. $\mathrm{P}<0.05$ was defined statistically significant, and $\mathrm{p}<0.01$ was defined especially significant different.

\section{Results}

MEOX2 expression levels correlated with larynx carcinoma progression. MEOX2 expression levels in laryngeal carcinoma tissues were determined by RT-qPCR and Western blot to determine MEOX2 biological function in this malignancy. The assays demonstrated that MEOX2 expression levels were significantly decreased in larynx carcinoma tissues compared to normal larynx tissues, both in mRNA and protein levels ( $p<0.05$, Figures $1 \mathrm{~A}-\mathrm{C}$ ). Figure $1 \mathrm{~B}$ shows the representative images of Western blot. While no statistically difference in MEOX2 levels was found for age, clinical pathological features such as TNM stages and histological differentiated grades of laryngeal carcinoma correlated with MEOX2 levels (Table 2). Carcinomas in the III and IV stages or well differentiated grades had lower MEOX2 levels. Finally, survival analysis showed that laryngeal carcinoma patients with higher MEOX2 levels (higher than in para-carcinoma tissue) had longer survival times than patients with lower MEOX2 levels (lower than in para-carcinoma tissue) (Figure 1D).

Over-expression of MEOX2 inhibited cell viability of laryngeal cancer cells. MEOX2 levels in Hep-2, TU212, AMC-NH-8 and TU686 laryngeal cancer cell lines were investigated to elucidate MEOX2 biological function in carcinoma of the larynx. The results suggested that MEOX2 expression levels were lower in laryngeal cancer cells than in normal laryngeal cells; with the lowest in TU212 cells which were chosen for further study $(\mathrm{p}<0.05$, Figures $2 \mathrm{~A}, \mathrm{~B})$. We then constructed a MEOX2 over-expression model by transfecting MEOX2 into TU212 cells in order to determine MEOX2 molecular mechanisms in laryngeal cancer cells. The detected MEOX2 mRNA and protein levels significantly increased in the MEOX2 group compared to $\mathrm{NC}$ and Control groups ( $\mathrm{p}<0.01$, Figures $2 \mathrm{C}, \mathrm{D})$. The cell viability of MEOX2 group was evaluated by CCK-8 assay and viability was timedependently inhibited to $81.3 \%$ at 12 hours, $62.8 \%$ at 24 hours, and $52.6 \%$ at 48 hours compared to NC and Control groups ( $\mathrm{p}<0.05$, Figure $2 \mathrm{E})$.

Over-expression of MEOX2 inhibited laryngeal cancer cell apoptosis.

The inhibitory function of MEOX2 stimulated us to examine TU212 cell apoptosis rates 48 hours after MEOX2 transfection. The apoptosis rates were examined by Annexin-V/PI double staining assay, and results indicated that MEOX2 over-expression improved cell apoptosis rates significantly to 7 -fold the apoptosis rates in $\mathrm{NC}$ and Control groups $(p<0.05$, Figure $3 \mathrm{~A})$. We then measured the expression levels of apoptosis related factors, and RT-qPCR and Western blot demonstrated that the Cleaved-caspase- 3 mRNA and protein levels were significantly increased and $\mathrm{C}-\mathrm{Myc}$ and XIAP were notably decreased in the MEOX2 group compared to the $\mathrm{NC}$ and Control groups $(\mathrm{p}<0.01$, Figures 3B, 3C). This confirmed that MEOX2 over-expression promoted cell apoptosis of TU212 cells by regulating the expression of apoptosis-related factors.

Table 2. Tissue assay of MEOX2 expression in laryngeal carcinoma.

\begin{tabular}{|c|c|c|c|c|}
\hline \multirow{2}{*}{ Factors } & & \multicolumn{2}{|c|}{ MEOX2 levels } & \multirow{2}{*}{ p-values } \\
\hline & & Lower & Higher & \\
\hline \multirow{2}{*}{ Age (years) } & $<60$ & 14 & 6 & \multirow{2}{*}{0.550} \\
\hline & $\geq 60$ & 16 & 10 & \\
\hline \multirow{2}{*}{ TNM stages } & I, II & 6 & 9 & \multirow{2}{*}{$0.024^{\star}$} \\
\hline & III, IV & 23 & 8 & \\
\hline \multirow{2}{*}{ Histological grade } & Middle differentiated & 5 & 9 & \multirow{2}{*}{$0.005^{\star *}$} \\
\hline & Well differentiated & 25 & 7 & \\
\hline
\end{tabular}

${ }^{*} \mathrm{p}<0.05$, Chi-square test. 

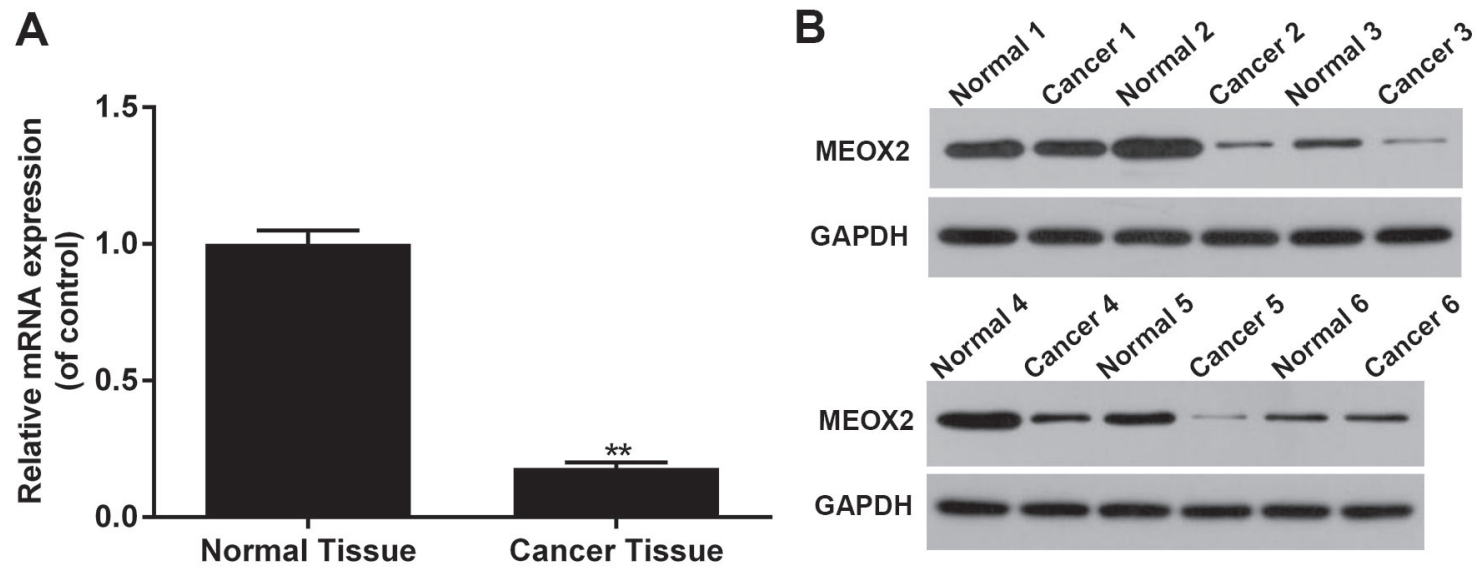

C
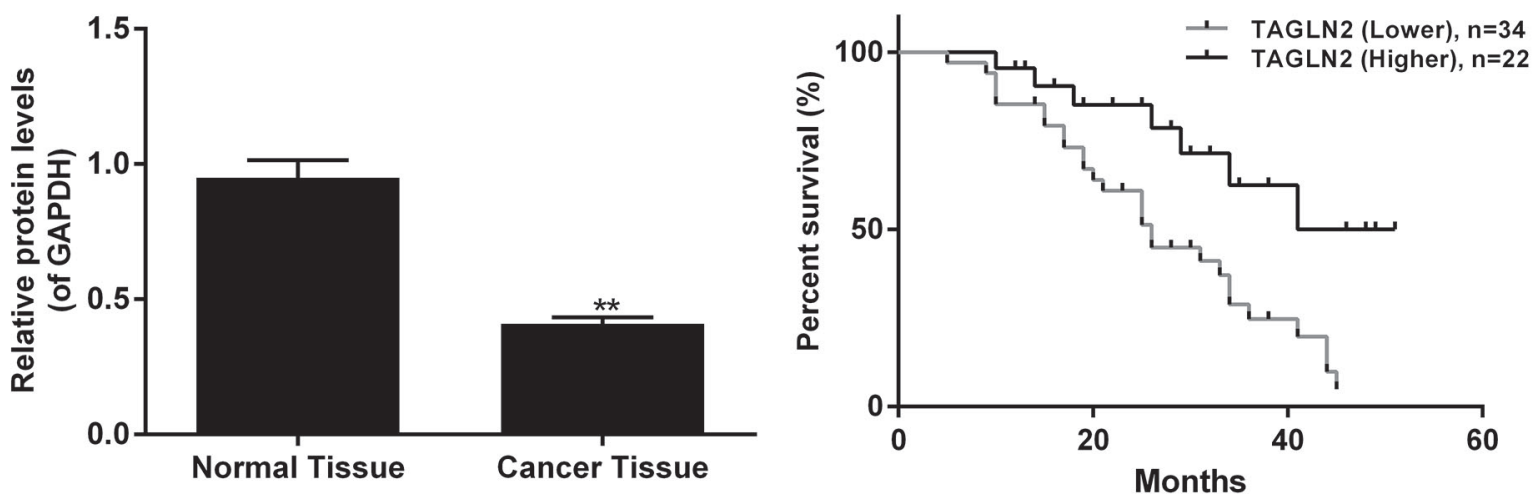

Figure 1. The expression levels of MEOX2 correlated with progression of larynx carcinoma. The mRNA and protein levels of MEOX2 in larynx carcinoma tissues were measured by RT-qPCR (A) and Western blot (B and C). B) The representative Western blot bands are presented. D) The survival time of larynx carcinoma patients and MEOX2 expression levels were analyzed. ${ }^{*} \mathrm{p}<0.01$ vs. Normal Tissue group.

A

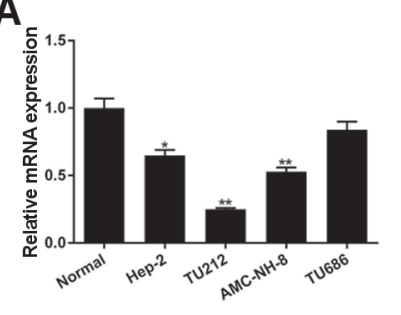

C

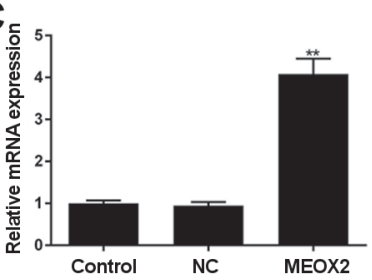

B

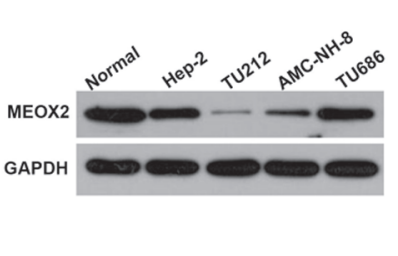

D

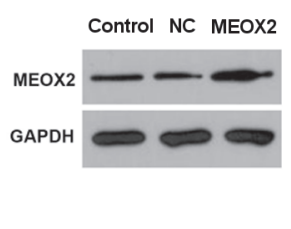

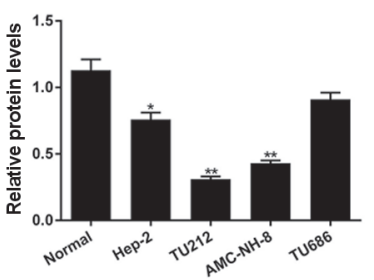
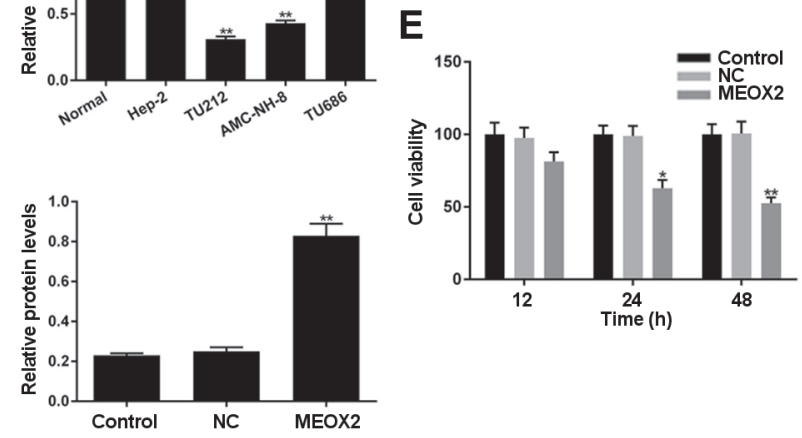

Figure 2. Over-expression of MEOX2 inhibited cell viability of laryngeal cancer cells. (A and B) The mRNA and protein levels of MEOX2 were detected by RT-qPCR (A) and Western blot (B) respectively in Hep-2, TU212, AMC-NH-8 and TU686 laryngeal cancer cells. (C and D) The mRNA and protein levels of MEOX2 were determined by RT-qPCR (C) and Western blot (D) respectively after MEOX2 transfection in TU212 cells. E) Cell viability was evaluated by CCK-8 assay at determined times (12, 24 and 48 hours). ${ }^{* *} \mathrm{p}<0.01$ vs. Normal cell group. 
Over-expression of MEOX2 inhibits the PI3K/Akt pathway in laryngeal cancer cells. We next examined MEOX2's effect on the PI3K/Akt pathway because of the pathway's importance in tumor progression. Western blot was conducted to evaluate the protein levels of PI3K p110a, PI3K p110 3 , PI3K class III, p-Akt and Akt and to determine their roles in activating the PI3K/Akt pathway. The immunoblotting assay showed that these expression levels decreased significantly $(\mathrm{p}<0.01)$ in the MEOX2 group compared with $\mathrm{NC}$ and Control groups $(\mathrm{p}<0.01)$; except for little change in Akt (Figures 4A, B). The results indicated that MEOX2 promotion of apoptosis in laryngeal cancer TU212 cells was effected by PI3K/Akt pathway inhibition.

\section{Discussion}

Although genetic factors have been recognized as very important in the pathogenesis of recurrent laryngeal carcinoma, early diagnosis and treatment remains unresolved. It is therefore imperative to search for novel suppressor genes which could solve this problem. MEOX2 is reported to inhibit cell proliferation and EMT in vascular smooth muscle cells and to play an important part in lung cancer prognosis and therapy [20] [23], and it has now become urgent to investigate the molecular mechanism of MEOX2 function in carcinoma of the larynx.

Herein, we established that MEOX2 expression levels were notably lower in carcinoma tissue than in normal
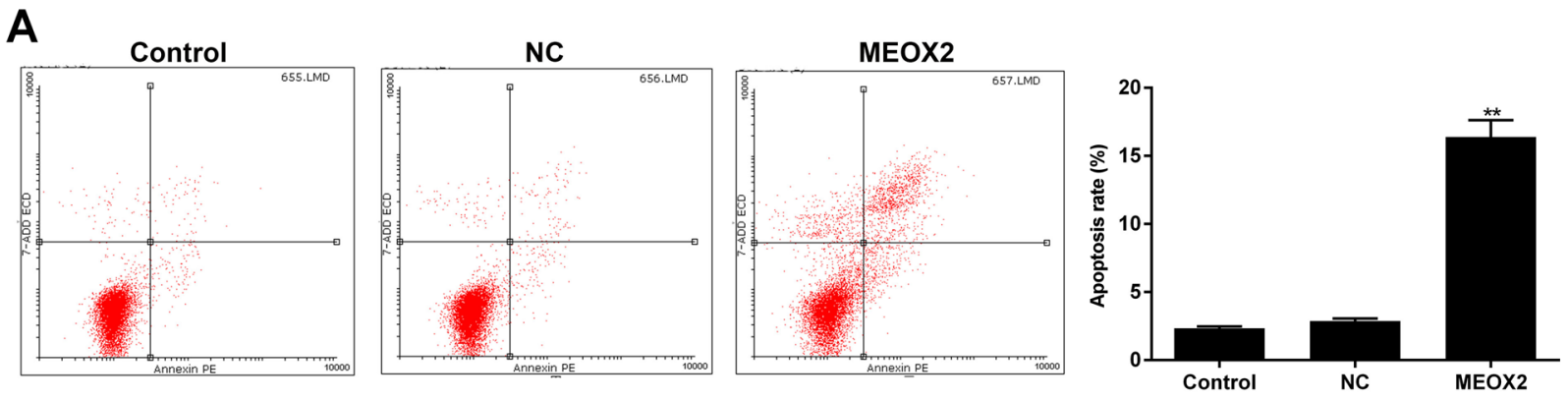

B

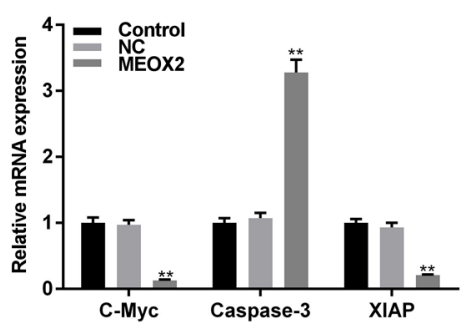

C

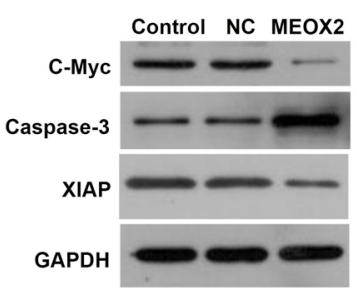

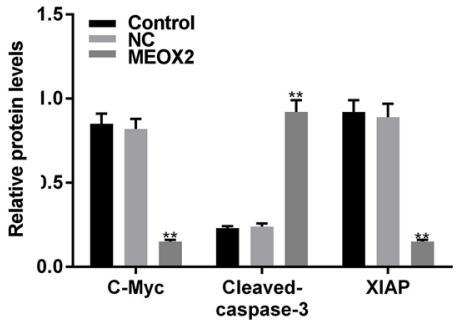

Figure 3. Over-expression of MEOX2 promoted cell apoptosis in laryngeal cancer cells. (A) Cell apoptosis were measured by Annexin-V/PI staining assay after MEOX2 transfection. (B and C) The expression levels of apoptosis related factors were examined by RT-qPCR (B) and Western blot (C) respectively. ${ }^{* *} \mathrm{p}<0.01$ vs. $\mathrm{NC}$ group.

A

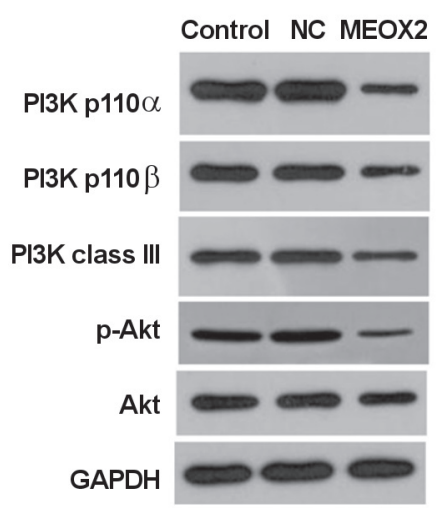

B

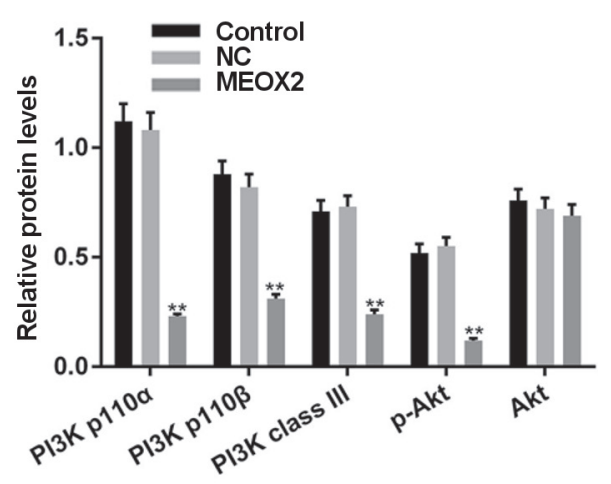

Figure 4. Over-expression of MEOX2 inhibited the PI3K/Akt pathway in laryngeal cancer cells. (A and B) The protein levels of PI3K/Akt pathway factors were determined by Western blot. ${ }^{* *} \mathrm{p}<0.01$ vs. NC group. 
tissue. Moreover, much lower MEOX2 expression levels were found in the advanced stages and higher grades of laryngeal carcinoma, and patients with lower expression levels had shorter survival time. This confirms MEOX2's critical role in laryngeal carcinoma progression, so we then applied the MEOX2 over-expression technique on laryngeal cancer cells to elucidate MEOX2 functional mechanisms. The TU212 cell line was chosen for MEOX2 overexpression study because it exhibited the lowest MEOX2 laryngeal cell expression level.

Apoptosis is programmed cell death and it is essential for normal cell biological function. It is related to the activation and regulation of a series of genes conserved in species. An example is the $\mathrm{C}-\mathrm{Myc}$ proto-oncogene which is the $\mathrm{X}$-linked XIAP inhibitor of apoptosis protein and Caspase-3 apoptotic promotion factor [24]. Caspase-3 is called the death protease because it is a critical executive protease whose activation leads inevitably to apoptosis $[25,26]$. The C-Myc transcription factor is found constitutively expressed in many cancers; including lung, stomach, breast and colon cancer and also in cervical carcinoma [27-30]. C-Myc stimulates the expression of many genes and it promotes cell proliferation and inhibits apoptosis [31] [32].

In contrast, XIAP is the strongest inhibitor of apoptosis in the IAP family and exerts its major caspase-inhibition directly $[33,34]$. Over-expression of XIAP is found in most cancer cells, and it correlates with tumor progression, poor prognosis and drug resistance $[35,36]$. The abnormal activation of cell proliferation and apoptosis inhibition are found in many cancers, including laryngeal cancer [37].

Hence, inhibition of cell proliferation and the activation of apoptosis provide the possibility of suppressing cancer progression. Consistent with previous research, our study demonstrated that TU212 laryngeal cancer cell viability was significantly inhibited in a time-dependent manner by MEOX2 over-expression, and cell apoptosis was dramatically promoted.

Further, RT-PCR and Western blot assays indicated that this process depended on Caspase- 3 activation and C-Myc and XIAP inhibition; and this provides further evidence that the MEOX2 effect of inhibiting cell viability and promoting apoptosis inhibits laryngeal cancer progression by regulating apoptosis-related genes.

$\mathrm{PI} 3 \mathrm{~K} /$ Akt signaling is regarded as a classic anti-apoptotic pathway [38] [39]. PI3K has three classes; I, II, and III. The most widely studied is PI3K class I which can be activated by cell surface receptors [40]. PI3K class 1 is also divided into subtypes IA and IB which transmit signals from tyrosine kinase-coupled receptors and G-protein-coupled receptors respectively. The catalytic $p 110 \alpha$ and $p 110 \beta$ IA subunits are now becoming important research tools and PI3K p110a has been reported to be frequently mutated in many cancers including head and neck squamous cell carcinoma [41].

PI3K also directly catalyzes downstream substrates to activate the Akt signaling pathway [42, 43], and abnormal
PI3K/Akt pathway activation often exists in most cancers; especially including laryngeal cancer [22, 44].

The over-expression of MEOX2 established in our research inhibited the expression levels of the following subtypes; PI3K p110a, PI3K p110ß, PI3K class III and p-Akt. This confirms that MEOX2 suppressed cell viability and promoted apoptosis by regulating the PI3K/Akt pathway, and the action consisted of suppressing the above five PI3K subtypes and activating Akt.

In conclusion, MEOX2 proves an effective novel cancersuppressor because it can inhibit cell viability and promote apoptosis in laryngeal cancer cells by regulating apoptosisrelated factors and the PI3K/Akt pathway. MEOX2 expression correlates with the carcinoma progression, and hence future research could well be based on in vivo investigation of MEOX2 treatment of this cancer. Finally, MEOX2 is a broadprospected target gene and it could well contribute to earlystage diagnosis, gene treatment and prognosis of carcinoma of the larynx.

\section{References}

[1] WINIARSKI P, LEWANDOWSKI A, GRECZKA G, BANASZEWSKI J, KLIMZA $\mathrm{H}$ et al. Primary and salvage laser surgery of 341 glottic cancers-Comparison of treatment outcomes between University Head Neck Tertiary Referral Center and Local Head Neck Department. Lasers Surg Med 2017; 50: 311-318. https://doi.org/10.1002/lsm.22759

[2] BHANDARI A, WANG YH, LV SX, XIA EJ, WANG OC. Novel strategy of stents in thyroid mass: a case series report of managing severely dyspneic patients. Onco Targets Ther 2017; 10: 4997-5004. https://doi.org/10.2147/OTT.S145418

[3] BRITT CJ, GOURIN CG. Contemporary management of advanced laryngeal cancer. Laryngoscope Investig Otolaryngol 2017; 2: 307-309. https://doi.org/10.1002/lio2.85

[4] KIM JW, BYEON HK, CHOI HS, LEE IJ. Dose de-escalation to the normal larynx using conformal radiotherapy reduces toxicity while maintaining oncologic outcome for T1/T2 glottic cancer. Sci Rep 2017; 7: 15732. https://doi. org/10.1038/s41598-017-15974-6

[5] MANNELLI G, LAZIO MS, LUPARELlO P, GALLO O. Conservative treatment for advanced T3-T4 laryngeal cancer: meta-analysis of key oncological outcomes. Eur Arch Otorhinolaryngol 2018; 275: 27-38. https://doi.org/10.1007/ s00405-017-4799-x

[6] SHAIKH MH, KHAN AI, SADAT A, CHOWDHURY AH, JINNAH SA et al. Prevalence and types of high-risk human papillomaviruses in head and neck cancers from Bangladesh. BMC Cancer 2017; 17: 792. https://doi.org/10.1186/s12885017-3789-0

[7] WU Z, LU B, LI X, MIAO W, LI J et al. MicroRNA-26a inhibits proliferation and tumorigenesis via targeting CKS2 in laryngeal squamous cell carcinoma. Clin Exp Pharmacol Physiol 2018; 45: 444-451. https://doi.org/10.1111/14401681.12890 
[8] LIU J, SHUANG Y, LI C, ZHOU X, HUANG Y et al. Expression of DCUN1D1 in laryngeal squamous cell carcinoma and its inhibiting effect on TU-177 cells after interfered by RNA. Clin Exp Pharmacol Physiol 2018; 45: 461-466. https://doi. org/10.1111/1440-1681.12893

[9] HE SS, CHEN Y, WANG HZ, SHEN XM, SUN P et al. Loss of LKB1 Expression Decreases the Survival and Promotes Laryngeal Cancer Metastasis. J Cancer 2017; 8: 3548-3554. https://doi.org/10.7150/jca.20535

[10] DOUVILLE JM, CHEUNG DY, HERBERT KL, MOFFATT T, WIGLE JT. Mechanisms of MEOX1 and MEOX2 regulation of the cyclin dependent kinase inhibitors p21 and p16 in vascular endothelial cells. PLoS One 2011; 6: e29099. https:// doi.org/10.1371/journal.pone.0029099

[11] MANKOO BS, COLLINS NS, ASHBY P, GRIGORIEVA E, PEVNY LH et al. Mox2 is a component of the genetic hierarchy controlling limb muscle development. Nature 1999; 400: 69-73. https://doi.org/10.1038/21892

[12] WEIR L, CHEN D, PASTORE C, ISNER JM, WALSH K. Expression of gax, a growth arrest homeobox gene, is rapidly down-regulated in the rat carotid artery during the proliferative response to balloon injury. J Biol Chem 1995; 270: 5457-5461.

[13] GORSKI DH, LEAL AJ. Inhibition of endothelial cell activation by the homeobox gene Gax. J Surg Res 2003; 111: 91-99.

[14] VALCOURT U, THUAULT S, PARDALI K, HELDIN CH, MOUSTAKAS A. Functional role of Meox2 during the epithelial cytostatic response to TGF-beta. Mol Oncol 2007; 1: 55-71. https://doi.org/10.1016/j.molonc.2007.02.002

[15] ARMAS-LOPEZ L, PINA-SANCHEZ P, ARRIETA O, DE ALBA EG, ORTIZ-QUINTERO B et al. Epigenomic study identifies a novel mesenchyme homeobox2-GLI1 transcription axis involved in cancer drug resistance, overall survival and therapy prognosis in lung cancer patients. Oncotarget 2017; 8: 67056-67081. https://doi.org/10.18632/oncotarget.17715

[16] CHIAPPINI PBO, DE MEDEIROS IUD, LIMA LGC, FREGNANI JH, NONOGAKI S et al. Prognostic implications of phosphatidylinositol 3-kinase/AKT signaling pathway activation in gastric carcinomas. Arch Med Sci 2017; 13: 1262-1268. https://doi.org/10.5114/aoms.2016.60394

[17] LIU Z, WANG F, ZHOU ZW, XIA HC, WANG XY et al. Alisertib induces G2/M arrest, apoptosis, and autophagy via PI3K/Akt/mTOR- and p38 MAPK-mediated pathways in human glioblastoma cells. Am J Transl Res 2017; 9: 845873.

[18] ZHAO J, ZHU J, LV X, XING J, LIU S et al. Curcumin potentiates the potent antitumor activity of ACNU against glioblastoma by suppressing the PI3K/AKT and NF-kappaB/ COX-2 signaling pathways. Onco Targets Ther 2017; 10: 5471-5482. https://doi.org/10.2147/OTT.S149708

[19] WANG H, DENG X, ZHANG J, OU Z, MAI J et al. Elevated Expression of Zinc Finger Protein 703 Promotes Cell Proliferation and Metastasis through PI3K/AKT/ GSK-3beta Signalling in Oral Squamous Cell Carcinoma. Cell Physiol Biochem 2017; 44: 920-934. https://doi. org/10.1159/000485360
[20] GARCIA-CARRACEDO D, VILLARONGA MA, ALVAREZ-TEIJEIRO S, HERMIDA-PRADO F, SANTAMARIA I et al. Impact of PI3K/AKT/mTOR pathway activation on the prognosis of patients with head and neck squamous cell carcinomas. Oncotarget 2016; 7: 29780-29793. https://doi. org/10.18632/oncotarget.8957

[21] LUO XM, XU B, ZHOU ML, BAO YY, ZHOU SH et al. Co-Inhibition of GLUT-1 Expression and the PI3K/Akt Signaling Pathway to Enhance the Radiosensitivity of Laryngeal Carcinoma Xenografts In Vivo. PLoS One 2015; 10: e0143306. https://doi.org/10.1371/journal.pone.0143306

[22] XU YY, WU TT, ZHOU SH, BAO YY, WANG QY et al. Apigenin suppresses GLUT-1 and p-AKT expression to enhance the chemosensitivity to cisplatin of laryngeal carcinoma Hep-2 cells: an in vitro study. Int J Clin Exp Pathol 2014; 7: 3938-3947.

[23] ZHANG J, HSU BAJ, KINSETH BAM, BJELDANES LF, FIRESTONE GL. Indole-3-carbinol induces a G1 cell cycle arrest and inhibits prostate-specific antigen production in human LNCaP prostate carcinoma cells. Cancer 2003; 98 : 2511-2520. https://doi.org/10.1002/cncr.11844

[24] THORNBERRY NA, LAZEBNIK Y. Caspases: enemies within. Science 1998; 281: 1312-1316.

[25] JIA J, DAI S, SUN X, SANG Y, XU Z et al. A preliminary study of the effect of ECRG4 overexpression on the proliferation and apoptosis of human laryngeal cancer cells and the underlying mechanisms. Mol Med Rep 2015; 12: 5058-5064. https://doi.org/10.3892/mmr.2015.4059

[26] CRYNS V, YUAN J. Proteases to die for. Genes Dev 1998; 12 : 1551-1570.

[27] COSKUNPINAR E, OLTULU YM, ORHAN KS, TIRYAKIOGLU NO, KANLIADA D et al. Identification of a differential expression signature associated with tumorigenesis and metastasis of laryngeal carcinoma. Gene 2014; 534: 183-188. https://doi.org/10.1016/j.gene.2013.10.063

[28] DAI MY, FANG F, ZOU Y, YI X, DING YJ et al. Downregulation of Notch1 induces apoptosis and inhibits cell proliferation and metastasis in laryngeal squamous cell carcinoma. Oncol Rep 2015; 34: 3111-3119. https://doi.org/10.3892/ or.2015.4274

[29] LIU Y, GONG LP, DONG XL, LIU HG. Detection of CMYC oncogene translocation and copy number change in the normal-dysplasia-carcinoma sequence of the larynx by fluorescence in situ hybridization. Diagn Cytopathol 2013; 41: 515-519. https://doi.org/10.1002/dc.22879

[30] WEI X, HE J, GAO J, CHEN J, WANG J. [Investigation of self-renewal mechanism about CD133+ cancer stem cells in human laryngeal carcinoma Hep-2 cell line]. Lin Chung Er Bi Yan Hou Tou Jing Wai Ke Za Zhi 2014; 28: 1636-1641.

[31] ZHANG WD, CHEN HX, WANG YX, CHEN ZP, SHAN ZJ et al. Bioinformatic analysis of c-Myc target from laryngeal cancer cell gene of laryngeal cancer. J Cancer Res Ther 2016; 12: 58-61. https://doi.org/10.4103/0973-1482.146083

[32] LIU L, WANG Y, SANG J. [Expression and significance of pStat3 and its downstream gene c-myc in laryngeal squamous cell carcinoma tissue and cell line]. Lin Chung Er Bi Yan Hou Tou Jing Wai Ke Za Zhi 2016; 30: 123-125. 
[33] WANG R, LI B, WANG X, LIN F, GAO P et al. Inhibiting XIAP expression by RNAi to inhibit proliferation and enhance radiosensitivity in laryngeal cancer cell line. Auris Nasus Larynx 2009; 36: 332-329. https://doi.org/10.1016/j. anl.2008.08.006

[34] HAO Q, LI X, LU X. [Antisense oligonucleotides targeting $\mathrm{XIAP}$ induce apoptosis and enhance radiotherapeutic activity against hep-2 cells in vitro]. Lin Chung Er Bi Yan Hou Tou Jing Wai Ke Za Zhi 2007; 21: 970-972.

[35] LI X, MA X, LU X, CUI L, DONG W. [Expression of inhibitor of apoptosis protein XIAP in laryngeal carcinoma and its clinicopathological significance]. Lin Chung Er Bi Yan Hou Tou Jing Wai Ke Za Zhi 2007; 21: 973-975.

[36] HAO Q, ZHANG Y, LIU C, LU X, ZHANG H. [Radiation induced apoptosis and $\mathrm{X}$ linked inhibitor of apoptosis expression in Hep-2 cells]. Lin Chung Er Bi Yan Hou Tou Jing Wai Ke Za Zhi 2009; 23: 387-390.

[37] JIANG L, WU X, WANG P, WEN T, YU C et al. Targeting FoxM1 by thiostrepton inhibits growth and induces apoptosis of laryngeal squamous cell carcinoma. J Cancer Res Clin Oncol 2015; 141: 971-981. https://doi.org/10.1007/s00432014-1872-3

[38] MOU S, ZHOU Z, HE Y, LIU F, GONG L. Curcumin inhibits cell proliferation and promotes apoptosis of laryngeal cancer cells through Bcl-2 and PI3K/Akt, and by upregulating miR-15a. Oncol Lett 2017; 14: 4937-4942. https://doi. org/10.3892/ol.2017.6739
[39] SI F, SUN J, WANG C. MicroRNA-138 suppresses cell proliferation in laryngeal squamous cell carcinoma via inhibiting EZH2 and PI3K/AKT signaling. Exp Ther Med 2017; 14: 1967-1974. https://doi.org/10.3892/etm.2017.4733

[40] QIU W, SCHONLEBEN F, LI X, HO DJ, CLOSE LG et al. PIK3CA mutations in head and neck squamous cell carcinoma. Clin Cancer Res 2006; 12: 1441-1446. https://doi. org/10.1158/1078-0432.CCR-05-2173

[41] SAMUELS Y, WANG Z, BARDELLI A, SILLIMAN N, PTAK J et al. High frequency of mutations of the PIK3CA gene in human cancers. Science 2004; 304: 554. https://doi. org/10.1126/science.1096502

[42] BAYASCAS JR. Dissecting the role of the 3-phosphoinositide-dependent protein kinase-1 (PDK1) signalling pathways. Cell Cycle 2008; 7: 2978-2982. https://doi.org/10.4161/ cc.7.19.6810

[43] WANG HX, TANG C. Galangin suppresses human laryngeal carcinoma via modulation of caspase- 3 and AKT signaling pathways. Oncol Rep 2017; 38: 703-714. https://doi. org/10.3892/or.2017.5767

[44] YANG LY, HE CY, CHEN XH, SU LP, LIU BY et al. Aurora kinase A revives dormant laryngeal squamous cell carcinoma cells via FAK/PI3K/Akt pathway activation. Oncotarget 2016; 7: 48346-48359. https://doi.org/10.18632/oncotarget. 10233 